\title{
ПРИМЕНЕНИЕ ИНФОРМАЦИОННЫХ ТЕХНОЛОГИЙ ПРИ СОПРОВОЖДЕНИИ СОЦИАЛЬНЫХ ПРОЕКТОВ
}

\author{
Бронников Сергей Анатольевич \\ к.пед.н., профессор \\ Черникова Марина Сергеевна \\ к.пед.н., доцент \\ Черников Илья Сергеевич
}

студент 2 курса

Бирский филиал БашГУ

Аннотация: В статье рассматривается понятие «социальный проект», его специфика, особенности информационного сопровождения при реализации проектов, авторы описывают опыт участия в грантовом конкурсе и реализации проекта «Big data в сфере конфессионального взаимодействия», его информационное сопровождение.

Ключевые слова: проект, социальный проект, информационное сопровождение, «Big data в сфере конфессионального взаимодействия».

\section{APPLICATION OF INFORMATION TECHNOLOGIES IN THE SUPPORT OF SOCIAL PROJECTS}

\section{Bronnikov Sergey Anatolyevich Chernikova Marina Sergeevna Chernikov Ilya Sergeevich}

\footnotetext{
Abstract: The article discusses the concept of "social project", its specifics, features of information support in the implementation of projects, the authors describe the experience of participating in the grant competition and the implementation of the project "Big data in the field of confessional interaction", its information support.

Key words: project, social project, information support, "Big data in the sphere of confessional interaction".
} 
В современной государственной политики Российской Федерации признаются приоритетными социальные задачи, в том числе в сфере поддержки социальных проектов финансированием. Огромный интерес вызывают проблемы по развитию отношений с центрами помощи семье и детям, бюро медико-социальной экспертизы, детскими оздоровительными и санаторнокурортными организациями, муниципальными органами, местными сообществами, государственными природными заповедниками, национальными парками, органами местного самоуправления, внутренним и международным туризмом социально-образовательного профиля.

Характерные для нашей страны социальные проблемы, нуждаются в разработке комплексной программы социальной политики, в качественном их информационном сопровождении. Но сначала определимся с понятием «социальный проект».

По мнению Мышковской О., «социальный проект - это четко спланированная программа действий, направленная на улучшение социального положения определенной категории людей, в которой участники проекта видят результаты своего труда и пользу, которую они несут обществу» [3].

Марков А.П. акцентирует внимание на том, что «социальный проект - это последовательность мероприятий и акций, целью которых является: предупреждение, минимизация или разрешение проблем, обусловленных дефицитами социально-культурной интеграции, адаптации, реабилитации, социализации, инкультурации и самореализации личности. Созданная на основе анализа ситуации взаимосвязанная последовательность мероприятий, действий и акций, обеспеченная в нормативно-правовом, экономическом и кадровом отношении, должна обеспечить изменение ситуации и создать условия, способствующие разрешению противоречий и трудностей личностного развития; оптимизации социально-культурной и социальнопсихологической среды обитания человека» [2].

Исходя их вышеперечисленных подходов к определению понятия, социальный проект есть сконструированная инициатором проекта четко спланированная последовательность мероприятий и акций.

Специфика любого современного социального проекта состоит в том, что в его информационном сопровождении так или иначе задействована сеть Интернет, где информация распространяется через специализированные форумы, социальные сети и сайты, что дает высокие результаты. Большинство социальных проектов обращено именно к молодежи, которые проводят много 
времени во всемирной сети, и задача современного специалиста по рекламе или PR - заинтересовать подобную аудиторию, привлечь ее внимание к социальному проекту. Интернет дает такую возможность, но только при грамотном подходе к созданию информационного продукта.

Большое количество информации, которую необходимо донести, может пройти мимо взгляда аудитории, попадая под понятие спам. Даже при таком весомом недостатке сети Интернет, существует множество достоинств этого способа коммуникации, а именно широкий охват «вещания», быстрое распространение информации, относительно малые затраты, возможность донести информацию о проекте точно до нужной аудитории, оперативное и более близкое общение с аудиторией. Последнее создает атмосферу причастности к реализации проекта даже при минимальных вкладах конкретного человека в проект.

Исходя из вышесказанного, можно утверждать, что социальная политика России остро нуждается в качественном информационном сопровождении социальных проектов.

Средства массовой информации - телевидение, радио, печатные издания, интернет-сайты - все это решающим образом влияет на то, как мы думаем и действуем. Ни одно изменение в обществе не возможно без участия СМИ. Если современное общество это организм, то информация - это его кровь, то без чего оно не может существовать.

Любой социальный проект - это инициатива, направленная на какое-либо изменение в обществе. Чаще всего, изменение касается мнений и отношений людей. Социальный проект нуждается в информационном сопровождении.

Под информационным сопровождением понимается использование традиционных СМИ в качестве основного канала для создания образа компании, информирования потребителей о продукте или услуге, рассказе о мероприятии и др., тогда речь будет идти об использовании классических PR-инструментов [1].

Существуют следующие виды информационной активности:

- Работа со СМИ: рассылка пресс-релизов, события для прессы (прессконференция, презентация, открытие/закрытие и т.д.), открытое письмо, интервью, кейс-история, занимательная статья и т.д.

- Наружная реклама (листовки, плакаты, баннеры), адресная рассылка, спам, флаеры и пригласительные, работа сайта, уличная агитация и т.д.

Информация попадает в СМИ через пресс-релиз. 
Информационный повод - то, что дает повод появлению какой-либо информации в СМИ (происшествие, событие, мероприятие, памятная дата, заявление VIP-персоны и т.д.).

Пресс-релиз - это информационное сообщение для СМИ, которое может служить основой для публикации, съемки телесюжета, записи радиоматериала. Фактически, это основной инструмент работы пиарщика со СМИ.

Медиа-карта - список СМИ с данными об их аудитории, тираже и направленности, имена конкретных журналистов и редакторов, их контакты. Используется при налаживании взаимодействия со СМИ (в частности, при рассылке пресс-релизов).

«Поставщик» информации (проектная группа, пресс-служба организации, пресс-секретарь VIP-персоны и т.д.) должен заранее тщательно готовить попадание информации в СМИ. Обзвон, рассылка, при необходимости личные встречи. При этом надо учитывать все особенности.

Изучив особенности информационного сопровождения социальных проектов, нами был разработан проект «Big data в сфере конфессионального взаимодействия». Данный проект был представлен на Региональном молодежном образовательном форуме «ТЕРРИТОРИЯ РОСТА - СМАРТ-ТАУ 5.0» и, при поддержки профессиональных экспертов, стал обладателем гранта Всероссийского конкурса молодежных проектов Республики Башкортостан.

Наш проект направлен на изучение социальной сферы человеческой деятельности средствами Больших данных.

Почти у каждого есть профиль в социальных сетях Twitter, Facebook, YouTube, ВКонтакте, Одноклассники и так далее. Мы постоянно оставляем «цифровые следы» в сети: лайки и дизлайки, фотографии, данные о дате рождения, месте учебы и работы, подписки на каналы и друзей, геолокация, просмотр видеофайлов, онлайн покупки, переводы денег и т.д. - все это возможно отследить и проанализировать.

Развитие технологий, позволяющих обрабатывать эти данные и генерировать на их основе новые решения и идеи - эта культура уже стала Big Data. B то же время Big data становится новой формой выражения культуры. Это новые способы видения себя и объектов культуры, создание нового интерфейса отношения к реальности. Используя большие данные можно изучить и особенности конфессионального взаимодействия.

Россия является многоконфессиональным государством. Так сложилось исторически на территории Российской Федерации живет великое множество народов. Все они во многом отличались друг от друга - своими традициями, национальной культурой, ну и, конечно же, верованиями. Поэтому в каждой 
российской семье свои традиции, религия, вероисповедание. И необходимо с уважением относится к чужой культуре, вере, может быть перенимать какие-то элементы, которые им по душе.

В переводе на русский confessio означает "вероисповедание". Как правило, этот термин используют при определении какого-либо направления в рамках той или иной религии. Отсюда следует, что межконфессиональные отношения - это взаимодействие между конфессиями и религиями.

Цель проекта: сформировать у обучающихся компетенции по анализу больших данных в сфере конфессиональных отношений, разработке проектов по межконфессиональным проблемам и результаты исследований представить на Научной школе «Big Data».

Участники проекта: Школьники и студенческая молодежь городов и районов Республики Башкортостан.

Были проведены следующие мероприятия проекта:

Первое мероприятие было посвящено обучения участников сбору больших социальных данных в сфере конфессиональных отношений в сопровождении цифрового тютера.

На следующем мероприятии участники разрабатывали свои проекты, инициативы и молодежные стартапы в сфере конфессионального взаимодействия, проводили анализ больших данных.

Итоговое мероприятие было представлено Научной школой «Big Data» по визуализации полученных больших социальных данных в сфере конфессионального взаимодействия в форме социальных проектов. На данном мероприятии приняли участие более 50 школьников и студентов Республики Башкортостан. Исследователями были проведены опросы по знанию праздников различных религий и народов, особенности их проведения, традиции, обычаи, кухня праздников. Так же исследовались вопросы отношения к семейным ценностям, роль религии в жизни человека, религиозные взгляды. Был представлен социальный проект «Поддержка беременных женщин и женщин с детьми, оказавшихся в трудной жизненной ситуации».

Исследования показали, что молодёжь интересуется проблемами межконфессиональных взаимоотношений, активно принимают участие в разных мероприятиях, праздниках, проводимые различными конфессиями. Однако есть проблемы информированности о традициях, обычаях, правилах религиозных учений, позволяющих объединять верующих, придерживающихся этого вероисповедания. 
Следующим этапом нашей работы предполагается разработка мобильного приложения «Big Data» для представителей различных конфессий, священнослужителей. Мобильное приложение это специально разработанное под функциональные возможности гаджетов программное обеспечение; это программный пакет, функционал и дизайн которого «заточен» под возможности мобильных платформ. Основные возможности приложения «Big Data»:

- Интерфейс программы создан конкретно под работу на мобильном устройстве через сенсорный экран или кнопки;

- Удобная и понятная для пользователей гаджетов навигация, мобильное меню;

- Лучшее взаимодействие с пользователем через сообщения, pushуведомления, напоминания. Приложение может выполнять функции даже в фоновом режиме. Для работы с программой не нужно открывать браузер, а многие приложения поддерживают ряд функций и при отключенном интернете;

- Хранение персональных данных пользователя. Эта функция расширяет возможности персонализации приложений. Например, приглашение большого числа участников для того или иного религиозного мероприятия.

Таким образом, наиболее востребованными и эффективными технологиями информационного сопровождения проектов являются на сегодняшний день технологии рекламы и связей с общественностью. Наиболее эффективно информация о проектах доносится до потенциальной аудитории через рекламное обращение в печатных изданиях, в сетке радиовещания, в телеэфире и в сети Интернет. Последний представляет собой наиболее динамично развивающийся ресурс с минимальными финансовыми вложениями (в отличие от телевизионной рекламы). PR-деятельность подразумевает распространение сведений о проекте путем использования источника информации от третьей стороны - работой со СМИ, организацией мероприятий событийного характера, благотворительной акцией и т.д.

\section{Список литературы}

1. Бронников С.А. Профессиональная коммуникативная компетентность руководителя ДОО. Монография. / С.А. Бронников, М.С. Черникова. Германия, изд-во: LAP LAMBERT Academic Publishing, 2018. - 87 с. 
2. Марков, А.П. Проектирование маркетинговых коммуникаций: Реламные технологии. Связи с общественностью. Спонсорская деятельность / А.П. Марков. - Ростов н/Д: Феникс, 2006. С. 404

3. Мышковская, О. Индекс бренда: сборник кейсов / О. Мышковская, М.: Индекс Дизайн \& Паблишинг, 2004. С. 45. 